\title{
If the Indicator Game is the Answer, Then What is the Question?
}

\author{
ALAN IRWIN \\ COPENHAGEN BUSINESS SCHOOL
}

\begin{abstract}
This contribution begins by arguing that indicators in themselves do not have effects, but that it is crucial to understand which questions in the wider culture and governance of academia their use speaks to. Drawing partly on the author's own experience in university management but also as an STS scholar, five important questions are presented to which indicators provide a kind of answer: ranging from public accountability over public research investment to intellectual and existential uncertainty. It is argued that understanding the wider institutional and professional logics is crucial if "better tunes" are to be developed in response to the indicator game: both to strengthen the standing and identity of the field and to support emerging scholars in this challenging context. The paper closes by inviting STSers--and particularly our professional institutions - to celebrate and, at the same time, take a stand for our diverse values, academic practices and notions of quality.
\end{abstract}

\section{Keywords}

indicators; metrics; academic careers

\section{Introduction}

The title of this debate contribution could sound a little too cute, even facetious. But that is not my intention. Instead, I will argue that unless we try to understand why the "indicator game" has assumed its present significance we have no possibility of getting to grips with it-never mind changing it. In making this case, I am specifically inspired by the quotation from Marilyn Strathern, also employed by Max and Sarah: "Auditors are not aliens: they are a version of ourselves" (1997: 319). Max and Sarah reasonably ask whether we could then be "other, better versions of ourselves" (Fochler and de Rijcke 2017). Myself, I wonder whether we even recognize ourselves-or the institutions we care for-in the current distorted reflection. But without at least some self-recognition we cannot hope to make a change.

\footnotetext{
Alan Irwin, Email: ai.ioa@cbs.dk
}

Copyright (C) 2017 (Alan Irwin). Licensed under the Creative Commons Attribution Non-commercial No Derivatives (bync-nd). Available at estsjournal.org. 
Between the lines, I draw here upon my own experience as an academic researcher but also as head of department, dean, acting president and vice president across three European universities. This long encounter with both academic management and research gives me a strong sense that the indicator game is not solely being imposed upon us from outside the university but is also driven by forces within. Actually, my first contact with the now-ubiquitous Google Scholar came in 2006 during a PhD workshop co-taught by myself and two highly distinguished STS scholars (let's just call them "Mike" and "Steve"). As I sat at the back of the room to enjoy my colleagues' presentations, one of the student participants pointed at her screen and quietly took me through a vaguely humiliating comparison of our citations. Incomprehension on my part soon gave way to curiosity. And of course I took a good look at the data when I got back to my hotel. Now it is commonplace in Europe for such evidence to appear in job applications, salary reviews and assessment reports--even when that information has not been officially requested.

I also write in the belief that, even if we as STS scholars may have been relatively (but not, as we will see, totally) quiet in this discussion, we do have something valuable to contribute. One could argue that STSers have a double connection to this issue: we bring an important critical perspective and a considerable volume of research relating to the politics of knowledge production and, at the same time, our own academic careers and professional lives are directly affected. Along the way, therefore, I will highlight some STS-related work that seems particularly relevant. Just to get us started, let me say that I approach the matter of indicators with at least four presuppositions in mind.

First of all, we should not forget one basic lesson from many years of STS scholarship: indicators in themselves do not have effects. This may sound rather obvious to all of us brought up on actor networks, social constructions and ideas of co-production. But it is, as previous scholarship also implies, very easy to slip into the language of indicators changing the university system or transforming the personal and professional experience of academic work. Indicators have been around for many decades. Equally, the point is not that individual indicators are inherently "bad." Instead, the metric cannot be removed from the larger culture that brings it meaning and shape-even as the use of metrics helps shape that culture. I remember well the amusement and genuine puzzlement among my former Manchester colleagues when we saw the outcome of what I believe was called the "research selectivity exercise" back in 1986. The underlying idea that our good friends and collaborators in neighboring departments should now be seen as "competitors" struck us as especially hilarious. Thirty years later, laughter might still be a very suitable response-but no one still thinks that this is a passing aberration.

Secondly, and here again I draw upon my own experience but also long exposure to comparative research, we should be careful when making universalized claims concerning "indicator culture." Even if both Britain and Denmark have national research quality assessments, these differ widely in their specifics and in their implications--and variations are evident within any one country. It seems from the 2015 4S session, where this "indicator game" debate got started, that the whole issue may (at least among STS scholars) be less attentionworthy in North America than in Europe. My point is not to downplay international trends and 
especially career pressures in a globalized academic market. It is rather to stress the very important contours of this discussion and the varying meanings and consequences of the "metric tide" (Wilsdon et al. 2015) across nations, regions, institutions, age groups and genders. Indicators are now everywhere, but one cannot just take it for granted that their significance is always the same.

Thirdly, there has been an important and highly critical treatment of this issue across the social sciences. When Rosalind Gill (2010) writes about the "hidden injuries of neo-liberal academia," I can only agree and wish I could express the ambiguities of "cruel optimism" so well. For me, one beneficial aspect of the "indicatorification" discussion is precisely that it has allowed personal and professional experiences to come to the fore and feelings of institutionallydriven but individually-experienced insecurity to be expressed. Nevertheless, I would argue that criticism is essential but not in itself sufficient. Somehow, we need not only to point to the indicators themselves but also engage (critically) with the mesh of meanings of which they form a part. What versions of ourselves and our institutions have been constructed--and on what basis?

Fourthly, and linked to all these points, it seems to me very plausible that our current experience of the "indicator-filled world" ${ }_{2}$ is strongly linked to what I can only refer to as a larger questioning of the role and purpose of the Academy. This is experienced in many countries as a rapid education-driven expansion of universities followed by a larger public and political discussion of the value of a university degree and of academic research-especially with regard to the social sciences and humanities. What, in these times, is a university for? (see for example Bok 2003; Irwin forthcoming; Kleinman 2003; Parker 2014). As a former dean, I know very well that when under external pressure one tends to reach for "hard evidence" of quality-for something (preferably in quantitative form) that will "make sense" in a policy environment. The slight curiosity here is that indicator-based evidence only seems to raise further questions among critical audiences. As an industrialist asked me after one shamelessly opportunistic ${ }^{3}$ presentation of my university's performance: But does any of this high-status research actually make a positive difference?

\section{Indicatoring the Academy}

So what then is going on within this co-produced process of what I clumsily referred to earlier as "indicatorification?" To return to my non-facetious title, what kinds of question are being asked and by whom? Let me try out just a few questions to which the indicator game provides a kind of distorted feedback. Bearing in mind my points above that indicators alone do not create impacts and that the significant nuances and contours of this discussion ought not to be forgotten, I do not mean to suggest that indicators are the inevitable answers to these questions-nor that the questions themselves are necessarily (or perhaps ever) posed in this "stripped down and cleaned up" fashion. Instead, I simply want to argue that there is a certain institutional and professional

${ }^{2}$ With thanks to one of my anonymous referees.

${ }^{3}$ To paraphrase the position of many university deans: "We know this ranking is dubious, but actually we come out of it really well." 
logic at work here and that, if we do not recognize this, then it will be impossible to learn what I will later refer to as "better tunes."

The first question is that of accountability-closely linked to that of the rationale for public research investment. One STS colleague, James Wilsdon, expresses this well in his broad case in support of the UK's Research Excellence Framework (REF) (2015). James specifically defends the "peer review, expert-led model of assessment that underpins the REF" against what he sees as the main alternative i.e. "a metric-based approach." In so doing, he vigorously argues that "the research community isn't being offered a return ticket to some (mostly mythical) golden age in which public funding was doled out, without any demands for accountability." James is quite right to note the difference between the REF (which still contains an important emphasis on peer review) and an entirely "metric" process. I don't have the space to go into that here--except to note that metric-based systems might appear especially attractive in smaller research environments such as the Scandinavian countries where a full REF process appears impractical. However, at least in a European context, the general argument that some measure of accountability is necessary when large amounts of public money are being spent seems to me inescapable. Of course, that does not in itself justify the indicatorification of academia. But it does provide a partial clue as to from where it emanates.

The second question concerns the issue of control at a distance. By this I mean the move, partly in response to the external pressures I alluded to earlier, to manage universities according to some kind of explicit bureaucratic principles (cost reduction, student throughput, transparency, coherent management structure, strategic coherence) rather than basically leaving decisions over staff and student recruitment, academic profile, funding allocation and workload organization to individual academic departments and centers. My source here will be the research policy scholar, Ben Martin. In a poignantly entitled article ("What is happening to our universities?"), Ben brilliantly poses the question: why, at a time when the management literature is emphasizing the benefits of "flatter organizational structures, decentralization and local autonomy," are so many universities moving in the opposite direction (Martin 2016)? Ben answers his own question in a number of ways, including the search for a certain form of "efficiency," the development of new public management and increased international competition. It is not too hard to see the link between, on the one hand, more centralized structures, larger units and increasingly intrusive administrative procedures, and, on the other, the call for standardization, improved management information and greater use of indicators. Ben Martin is especially concerned that assessment processes and performance indicators will drive research towards "safer," mono-disciplinary research and away from interdisciplinary, heterodox and risky scholarship (i.e. the very kind of academic work to which many STS scholars are specifically attracted).

The third question is that of "internationalization" and changing academic labor markets. My text for this will be the report of the group of STSers, including myself and chaired by Ulrike Felt, which addressed the challenge of "caring for our futures in turbulent times" (Felt et al. 2013). One of the several changing conditions for research and innovation observed by the Felt Report specifically concerned the nature of scientific occupational structures, including the 
growing importance of "rather narrowly defined career models." The combined effect of competing in a global job market and institutional "trust in numbers" in an apparently objective attempt to weigh an array of candidates represents a powerful drive towards the use of indicators-both on the part of universities but also early-career researchers themselves. Government policies that emphasize a particular form of "internationalization" (Linková and Stöckelová 2012) may further accentuate this perceived need for an externalized quality standard.

The fourth question is that of quality in "post normal" times. In their seminal article, Silvio Funtowicz and Jerome Ravetz (who again need no introduction to an STS audience) present post-normal science as occurring "when uncertainties are either of the epistemological or the ethical kind, or when decision stakes reflect conflicting purposes among stakeholders" (Funtowicz and Ravetz 1993: 750) As Silvio and Jerry rightly argue, one important element of these "new times" is that traditional understandings of quality assurance are "left in confusion." Whilst they try to look forward in a progressive direction (not least towards "extended peer communities"), it may be that in large areas of practice the question of quality in shifting circumstances has been answered in much less sophisticated and reflexive terms-and not least in the shape of the "indicator game."

Finally (at least for now), we have the question of professional and existential uncertainty. One aspect of Rosalind Gill's account that especially resonates is the individualizing nature of much indicator discourse-what she calls "toxic shame." This seems endless in its variety: moving in a heartbeat from "my paper has been sharply criticized" to "I am useless and will never find a decent job." I guess I experienced a mild form of this in the $2006 \mathrm{PhD}$ workshop mentioned earlier. Equally, it is not hard to see at work within the obsessive drive in many disciplines (although not especially STS) towards indicators, rankings and league tables an intellectual hollowness that seeks out indicators as a form of reassurance but also produces a sense of personal and professional anomie. As one of my senior colleagues reacted when an eager member of library staff calculated her (actually rather high) h-index: that doesn't seem like much for a lifetime's work. But let us acknowledge, too, that more traditional measures of reputation ("and where did you study as an undergraduate?") and academic ability ("a first-class mind") can also be deeply loaded and not least in class, ethnicity and gender terms.

These are not of course the only questions sustaining the indicator game. In addition, I would stress the important inter-connections between these. To return to the theme of the indicator game being driven from within as well as without (however we are to draw these borders), I have heard the same colleagues bragging that their latest paper has appeared in a highly-ranked journal—while saying absolutely nothing about the actual content-and then lamenting the growing practice of producing lists of "preferred journals." Research assessment exercises are often criticized for their impact on academic culture, but there seems to be no shortage of academics willing to serve on such panels and committees (I have even done it myself.) And it is not only university deans who are opportunistic in their use of indicators, which, whilst problematic in many ways, also support their cause. In the toughest position of all, those in insecure academic positions can find themselves negotiating the treacherous terrain of directly experiencing the negative consequences of the "indicator game," and having little choice 
but to live by it. Meanwhile, the publication demands only become greater-and way beyond the formal appointment requirements I had to meet at a similar career stage.

Hopefully, the five questions highlighted here do suggest something of the social and organizational contexts in which "the game" is defined and enacted by a variety of players. It follows for me that pointing out that the Emperor is not wearing so many clothes is an essential activity. But somehow we need to go further if we are to develop other ways of addressing (and, very importantly, reconstituting) these questions. Since we cannot actually boycott ourselves, we must find more constructive ways of sustaining scholarly values and exercising care and responsibility whilst recognizing the larger institutional forces at work. In my final section, I will try to open up these questions from the particular perspective of the STS community.

\section{On the Devil and the Best Tunes}

The challenges are undeniably large and pressing. However, and before we become totally downhearted, it is important to stress that the indicator game may be powerful but its hegemony is not complete-although of course experiences will vary. Paradoxically, the collegial and open mood at our session during the annual conference of the Society for Social Studies of Science (4S) in Denver demonstrated this very point. I even recall some ironic but also heartfelt laughter, suggesting that the irreverent spirit of 1980s Manchester is far from dead.

When faced with the contradictory logics of our academic and personal lives, institutional and intellectual contortions, and the sheer impossibility of meeting all the demands upon us, laughter is a reasonable (perhaps the most reasonable) response. However, laughter should not be the only reaction. Here, those who take on positions of leadership in our academic and professional organizations (and I would modestly put myself in that category) have a special responsibility. We need those who in different capacities represent STS to play some new--and actually rather old--tunes. And we need the greater STS community to ensure these tunes are heard within our journals, seminars and conferences but also more widely in our academic departments, engagement activities and cross-disciplinary collaborations. In so doing, we might even serve as a model for other scholarly communities (imagine that!).

I know that playing tunes might seem a frivolous response to what for many--and especially those struggling in temporary positions-is a deeply challenging situation. But without a sense of how things could be different, without a focus on constructive possibilities, and without a vigorously defended alternative approach, we will be doomed to the kind of handwaving and self-justifying critique which does very little to take us forward--and might even make things worse. I have chosen to present the following as a series of celebrations although other formats are of course possible (but please go easy on the dirges).

The first tune is one of celebrating the values and practices we hold dear. Rather than retreating in the face of external pressures, we should be sure to acknowledge those times and places when the academic life is not nasty, brutish, and short. This also means acknowledging, and as necessary defending, all those who play a part in maintaining these creative environments and working relations-whether they are "academic stars" or not. I could of course make a 
similar point about the journals, conferences, PhD supervisions and defenses, teaching programs, discussion and reading groups, edited collections and handbooks, letters of reference and exchanges of ideas that underpin our existence as scholars. Of course, no good tune is without a hint of melancholia, so we should not hold back from criticizing those times and places when these values and practices break down.

The second tune is one of celebrating quality in all its forms. Now is a very good time to make the public case for both academic and extended peer communities, to defend the openness of scholarly processes, and to communicate strongly the varying and contextualized meanings of quality. Indicators can be part of this tune, but there is much more to express and explore. Why not take the now-sanctified notion of "excellence" but give it new and augmented meanings: excellence in STS scholarship but also excellence in training graduate students and maintaining academic communities, excellence in working with citizen groups, excellence in challenging policy assumptions and excellence in contributing to intellectual and political debate? "Quality" is famously a difficult and sometimes controversial term. But our response should not then be to hand it over to reductionism and objectification. Equally, and as Ruth Müller (2017) relatedly discusses, quality is about crafting and maintaining a sense of meaning in our academic and professional work-a practice that unreflective pursuit of the indicator game can seriously undermine.

Not everyone will like my third tune, but let me offer it anyway: celebrating societal contribution and engagement. I do not think the question of accountability can (or should) be dodged-but it can certainly be addressed in a more compelling, imaginative and innovative fashion. And once again the point is not simply to accept the prevailing terms of measuring societal contribution. Instead, this issue can and should be addressed in diverse ways: from making the case for the intellectual value of research in our field to pointing out the different forms that "engagement" can take, from defending the need for serious criticism and intellectual challenge to communicating the ways in which STS research addresses fundamental sociotechnical issues (from climate change to you name it) in a manner which profoundly extends our conceptual, political and institutional capacities. This is also an argument for active experimentation and for reflexive-but-engaged forms of practice. I think the suggestion from Maximilian Fochler and Sarah de Rijcke (2017) concerning "evaluative inquiry" shares something of the same open, enabling and productive spirit.

STS scholars can and should turn their critical, imaginative and empirical attention to the contradictory logics and practices of the indicator game. However, the question must at least be asked whether STS is collectively doing enough to provide support for especially emergent scholars in this challenging context. Here of course I am inviting a discussion that goes beyond the limits of this short essay. Discussion of the indicator game may start out as a critique of others but curiously ends up as a consideration of how our own professional institutions and ways of working might best assist in these indicatored times.

And so to the final tune: celebrating future generations of STS scholars and teachers. This one needs to be played with particular energy. Everybody on the dance floor! 


\section{Acknowledgements}

This has been an unusually creative and collegial process. I would especially like to thank Maximilian Fochler and Sarah de Rijcke for taking this initiative and seeing it through in such a warm, accomplished and constructive sprit. Thanks also to the anonymous referees for their valuable input, to the journal editors and to Maja Horst for her patient re-readings of my text.

\section{Author Biography}

Alan Irwin is a professor in the Department of Organization at Copenhagen Business School (CBS). From 2007-2014 he was Dean of Research at CBS and in 2011 he was also CBS' Acting President.

\section{References}

Bok, D. 2003. Universities in the Marketplace: The Commercialization of Higher Education. Princeton and Oxford: Princeton University Press.

Felt, U., D. Barben, A. Irwin, P.-B. Joly, A. Rip, A. Stirling, and T. Stockelova. 2013. Science in Society: Caring for our Futures in Turbulent Times, ESF policy brief. Strasbourg: European Science Foundation.

Fochler, M. and S. de Rijcke. 2017. "Implicated in the Indicator Game? An Experimental Debate." Engaging Science, Technology, and Society 3: 21- 40. DOI:10.17351/ests2017.xxx.

Funtowicz, S. O. and J. Ravetz. 1993. "Science for the Post-Normal Age." Futures. September: 739755.

Gill, R. 2010. "Breaking the Silence: The Hidden Injuries of the Neoliberal University." In Secrecy and Silence in the Research Process: Feminist Reflections, edited by Róisín Ryan-Flood and Rosalind Gill, 228-244. London: Routledge.

Irwin, A. Forthcoming. "Mixing Oil and Water: On the Co-Production of Professional and Disciplinary Goals in the Modern Business School." In Commercialisation and the Business School, edited by Tony Huzzard, Mats Benner and Dan Kärreman. London and New York: Routledge.

Kleinman, D. L. 2003. Impure Cultures: University Biology and the World of Commerce. Madison: University of Wisconsin Press.

Linková, M. and T. Stöckelová. 2012. "Public Accountability and the Politicization of Science: The Peculiar Journey of Czech Research Assessment." Science and Public Policy 39 (5): 618-629.

Martin, B. 2016. "What is Happening to our Universities?" SPRU Working Paper. SWPS 2016-03. University of Sussex.

Muiller, R. 2017. "Crafting a Career in STS: Meaning Making, Assessment, and Interdisciplinary Engagement." Engaging Science, Technology, and Society 3: 84-91. DOI:10.17351/ ests2017.112.

Parker, M. 2014. “University, Ltd: Changing a Business School.” Organization. 21(2): 281-292. 
Strathern, M. 1997. "'Improving ratings': Audit in the British University System." European Review 5 (03): 305-321.

Wilsdon, J. 2015. "In Defence of the Research Excellence Framework." The Guardian (on-line). http:/ / www.theguardian.com/science/political-science/2015/jul/27/in-defence-of-the$\underline{\text { ref }}$

Wilsdon, J., L. Allen, E. Belfiore, P. Campbell, S. Curry, S. Hill, R. Jones, R. Kain, S. Kerridge, M. Thelwall, J. Tinkler, I. Viney, P. Wouters, J. Hill, and B. Johnson. 2015. The Metric Tide: Report of the Independent Review of the Role of Metrics in Research Assessment and Management. DOI: 10.13140/RG.2.1.4929.1363. HEFCE. 